\title{
An Analysis of Humanities Education in College English Teaching Weina Ouyang
}

Department of Public Foreign Language Education, Beihua University, Jilin City, Jilin Province, 132000

\begin{abstract}
It's conducted to research the current humanities education in college English teaching, taking the teaching class of the experimental group to carry on the sample survey, in which the lacking of humanities education is analyzed. According to the practice and characteristics of college English teaching, feasible strategies are proposed to integrate humanities education and college English teaching, which enrich foreign language teaching theories and initiate the college humanities education that proved by the practice.
\end{abstract}

Keywords: Humanities, Humanism; Instrumentalism; Integrity strategy; Construction mode

\section{人文素质教育在大学英语教学中的探析}

\author{
欧阳巍娜 \\ ( 北华大学 公共外语教育学院, 吉林 吉林 132000 )
}

摘要: 针对当今高校英语教学中人文素质教学的缺失现状, 选择试验组的教学班级进行抽样调查, 探析大学英语教学中 人文素质培养的综合情况, 分析人文素质育成缺失的原因, 结合高校大学英语的教学实际和特点, 建构人文素质教育和大学 英语教学一体化模式, 提出了大学英语教学中进行人文素质教育的可行性方案, 通过实践证明能有效促进学生综合素质的培 养, 也为外语教学理论提供新的角度观点和必要的补充。

关键词: 人文素质; 人文性；工具性；一体化策略；建构模式

中图分类号: H319 文献标志码: A

\section{引言}

教育部关于《大学英语课程教学要求》中明确指出 “大学英语的教学目标是培养学生的英语综合应 用能力, 特别是听说能力, 同时增强其自主学习能力, 提高综合文化素养, 以适应我国社会发展和国际 交流的需要”。大学英语作为高等教育中的必修课程, 尤其更多的使命, 不但承担着提高大学生英语能 力的责任, 对于学生的人文素质教育, 如拓展国际视野、了解世界文化, 提高个人情操等等都有不可忽 视的影响, 所以普遍人文外语教学兼有工具性和人文性。

二十一世纪中国教育改革的发展理念重点是全面推进素质教育, 所以在大学英语教学中必须要重视 学生的素质教育, 尤其是人文素质教育, 这是社会发展对人才素质的必然要求和结果。如何发挥人文教 育对学生个性潜能的开发、理想人格的追求、人生意义的启迪, 对个人和整个社会的发展意义重大而深 远，在高等教育中强化人文素质教育刻不容缓。

国内研究现状夜不容乐观。外语教学中素质教育缺失其实国内一直有学者研究和讨论, 但由于应试教 育的影响, 一直未有统一的方向和执行力度。王守仁在《我国高校大学英语教学现状调查及大学英语教学 改革与发展方向》中特别提出将人文教育引入英语教学环节, 英语作为人文学科之一, 应当担负起大学生 人文素质教育的重任, 重视英语教学中语言与文化的平衡。杜时忠的《人文教育论》里也在强调英语是人 文学科的一支, 英语学习的基本要素是英语语言、文学和文化。语言是文化的载体, 文化是语言的内容, 文化融于语言之中。此外, 《大学英语课程实施人文素质教育之策》、《从通识教育视角探讨中国大学英语 
教学改革》等多篇文章也探讨了通识英语在大学英语课程设置中的重要性; 另有一些学者一直致力研究人 文教育融入外语教学的模式和方法。

\section{1 分析英语教学中人文素质教育缺失的原因}

当今社会, 大学英语教学的重要考核指标是四、六级英语考试的通过率，有此压力，外语教学拘泥于 掌握语言知识和技能, 使学生学习视野狭窄, 文化意识薄弱, 而英语教学本身的特点, 如重知识灌输和机 械训练, 使得学生的想象力和创造力更加受阻, 阻碍人才培养。与此同时, 外语教学中的各种教学方法的 讨论和研究, 各种教学手段的更新和实施, 各种教学目标的设立和制定, 都缺乏对人文素质教育的关注, 主要体现在以下几个方面

\section{1 社会问题}

中国高等教育长久以来一直存在偏重于专业教育的问题，即 “重科技轻人文，重人才职业选择规格、 轻人才人格教养”。对于专业大于工具的传统观念影响时间长, 范围广, 不单单是在外语教学中有体现, 而是很多人文科目都有所忽视, 这些的确是造成人文素质教学受到忽视的原因, 但现在随着时代发展, 人 们越发意识到外语教学中的素质教育对于人才培养的重要性, 对于人才的英语素质要求也就越发提高。

\section{2 学校问题}

近些年来, 四、六级考试在某种程度上作为衡量大学英语教学成果的标准导致了英语教学中以应试能 力为主导的教学实施, 偏重外语的工具性价值。各方压力导致唯考试论, 唯成绩论, 学校的教学倾向不可 避免的向考试倾斜, 从教学内容, 教学手段, 教学模式都是根据应试辅导强化训练方向设计, 现在这种趋 向正在逐步调整。此外, 教师在专业素质、知识文化底蕴、知识素质和国际视野方面水平也参差不齐,

\section{3 学生问题}

从学生的角度来看, 学生本身忽视英语课程, 仅以过四、六级为唯一英语学习的目的, 缺乏英语学习 兴趣, 更少数同学对英语学习有排斥和厌倦感。少数同学对英语学习有排斥和厌倦感。学生不明白语言学 习对于个人素质提高的潜移默化作用，从主观到客观都忽视人文素质育成。

综上所述, 社会、学校、学生等多方面的情况直接影响教师的教学方向和专业方向。而教师的个人素 质和专业素质也反过来影响学生的素质培养。

\section{2 构建人文素质教育和大学英语教学一体化模式}

\section{1 人文素质教育在大学英语教学中的实践规划}

结合我校实际状况, 在我校大一学生中进行问卷调查, 分析人文素质育成的现状。根据试卷调查我校 学生对英语学习和个人素质育成关系的理解, 取样尽可能广泛, 涉及多个学院, 涵盖文理科多个专业。调 查内容包括教学课堂内容难易, 兴趣点, 资源利用, 西方文化和核心价值的辨识能力, 自主学习能力培养, 专业和英语目标关系，跨文化交际水平等方面。调查将问题细化和量化，用量化分析的方法统计学生人文 素质调查结果，将试验组和对照组的调查结果进行分析量化结果。实践调研分为三个阶段:

第一阶段：调研阶段，以问卷调查和调查分析为依据。

第二阶段：实践阶段，以新的素质育成教学模式应用到教学实践中。

第三阶段：总结阶段，总结分析教学实践阶段性的成果和问题反馈。

结果表明, 学生的素质育成从大学英语教学中获得甚少, 一方面, 大部分学生的英语基础无法支撑其 
了解学生想要了解的国际信息输入, 另一方面, 英语教学中的人文知识输出无法满足学生的需求。但是通 过新的素质育成教学模式的应用, 学生的潜在能力得以发挥, 自主学习能力增强, 人文素质培养得到了极 大的提高, 整体的英语素养明显提升。

\section{2 建构下的多元教学模式}

建构主义认为, 学生对知识和能力的掌握不仅与自身有关, 还与社会环境有关, 更强调知识构建过程 中社会性的一面。从这个角度看, 教师准备英语授课前, 应考虑学生的实际需要, 拟定重点、难点和学生 的兴趣点, 以教材为基础, 在基本授课内容的基础上大力加强人文素质熏陶。在课前将相关知识点的人文 背景作为预习内容布置, 引导学生将教学内容与实际生活联系起来; 课堂上以教师为主导, 以学生为主体, 师生之间、学生之间相互启发, 增强学生的学习主动性, 拓展学生思维, 扩展知识储备, 开拓眼界。在教 与学的双边关系中，启发和探究实现了有机的结合，学生的人文素质得到极大的提高。课内反馈出学生最 感兴趣的问题，在课内没有解决好，应从时间和空间两方面向课外延伸，让学生向图书馆、向网络、向社 会去继续探究。通过课内、课外相结合来完成知识的迁移和理性升华，达到教学目标的实现。

本研究中的难点是量化学生调查意见结果。研究拟订问题的设计基于人文素质教育特点在大学英语课 堂中的应用和实践, 同时参考文秋芳等和戴炜栋等关于学习观念的研究问卷。因子分析采用主成分分析法, 设定 4-5 个因子, 分别就学生英语学习的兴趣, 自主学习能力认知、团队互助学习认知、影像英语水平的 因素等方面进行调查，量化分析结果，根据结果设定课程安排及进行难易度考量。

\section{3. 人文素质教育在大学英语教学中实践策略}

总结之前教学实践中采用的新的以人文素质教育为核心的教学模式, 将人文教育和外语教学整合一体 化, 实践中需要注意几方面的转变。

\section{1 改革传统教学模式, 重视通识教育}

设立多元化的课堂教学目标, 英语教师在大学英语课堂教学中实践人文素质育成。展开对比, 感悟文 化魅力, 培养文化意识; 设置问题, 启迪思维, 培养批判和反思精神; 渗透美育, 体味语言魅力, 培养鉴 赏和审美能力; 探究主题, 学以致用, 培养实践和创新精神。多种教学模式能够激发学生的学习兴趣, 鼓 励学生的学习主动性, 师生互动大大加强。王守仁在《我国高校大学英语教学现状调查》中专门提到重视 通识英语教学, 旨在实现其教学目标中的 “提高综合文化素养的要求” , 通过了解, 才能以批判的眼光看 待西方文化及其核心价值, 丰富英语相关选修课, 一方面对专门用途英语中的术语英语和职业相关英语有 极大辅助作用, 另一方面对有英语兴趣的学生提供更多相关知识学习的资源。实践证明, 相应专业的选修 课开设, 极大地调动了学生学习英语的兴趣, 让学生在英语学习中促进专业技能学习, 在学习专业中提高 英语水平。

\section{2 转变英语教学指导思想, 促进全面素质教育}

教师要深入学习研究《大学英语教学大纲》的各项具体指标, 并在日常教学中抓好实践教学工作。要 树立技能培养只是手段的思想, 明确英语学习的最终目标是用英语进行交际并获取有关知识和信息, 自觉 地在教学实践注重学生语言能力的培养, 坚持课堂教学以学生为中心, 教育教学以 “学习为中心”, 运用 英语教学逐步推进学生素质的全面提升。从源头理清指导思想变英语技能教育为全面素质教育, 对于整体 教学是十分必要的。 


\section{3 丰富大学英语教学方式, 培养学生个性化发展}

除了课堂教学以外，创建丰富的人文校园文化氛围，营造良好的人文教育环境对加强人文素质教育是 十分有效的方法。大学英语教学应走出应试教育的狭监圈子, 冲破教材内容的束缚, 在遵循教学大纲的基 础上, 合理的整合教学内容, 拓展丰富的教学方式, 将人文素质教育与英语教学融合一体, 采用因材施教 的灵活教学方式, 培养学生的个性化发展, 利用各种多媒体资源, 如网络和广播等媒介都是大学英语教学 可以充分开发和利用的教学资源。

\section{4 增强英语教师人文素质教学认识, 提高教师自身素质}

教师作为这个社会的知识和精神文明的传导者, 肩负着引导学生正确的人生观和价值观的重要工作。 英语的学习不仅是一种语言的学习, 更重要的还是一种文化的学习, 英语教师不仅承担着培养具有国际视 野的人才的重任, 更应是人文精神的引导者和示范者, 作为文化传播者, 教师应该在日常教学中潜移默化 对学生素质育成的培养，教师本身也应该极大提高人文素质水平和教学能力。

\section{四、结论}

由于当代社会的竞争日益加剧，在多元思想的冲击下，学生往往会出现在人生观、价值观等方面的迷 茫, 由于大学英语是高校学生修读人数最多、时间跨度最长的一门公共人文课程, 所以将人文素质教育贯 彻入大学英语中是加强高校人文素质教育的重要方法之一。总而言之, 大学英语教学应为培养具有人文精 神、世界眼光及正确价值取向，同时具有一流专业技术的全面型人才做出应有的贡献。

本文旨在探讨如何更好的在大学英语教学中推进人文素质教育, 人文素质教育和外语教学的一体化可 行性研究和实践, 这对大学英语教学中一直以来都不受重视甚至缺失的素质教学内容、方法进行补充和建 议, 打破传统外语教学的固定框架。全社会从上到下都必须意识到人才培养的重要性, 高校更要肩负起培 养大学生人文素质的责任, 所以将人文素质教育贯彻入大学英语中是加强高校人文素质教育的重要方法之 一, 只有切实推进英语教育与人文素质教育的齐头并进, 才能使得当代大学生的英语知识水平和人文素质 水平同时迈向一个新的台阶。总之, 大学英语教学应为培养具有人文精神、世界眼光及正确价值取向, 同 时具有一流专业技术的全面型人才做出应有的贡献。

\section{参考文献}

[1] 王守仁．我国高校大学英语教学现状调查及大学英语教学改革与发展方向.中国外语，2011，08(5) : 4-11

[2] 戴卫平. 语言学理论语言教学.广州. 世界图书出版广东有限公司 2014.7

[3] 杜时忠. 人文教育的理念 $[J]$. 教育理论与实践. $1999(9): 2-7$

[4] 罗荷香. 大学英语课程实施人文素质教育之策略. 教育学术月刊, 2008(12):32-33

[5] 章黄. 从通识教育视角探讨中国大学英语教学改革 $[\mathrm{J}]$ 上海交通大学学报, 2007:32-33

[6] 钟启泉 汪霞 王文静. 课程与教学论 上海. 华东师范大学出版社, 2008.7

[7] 席风. 外语教学中人文教育探析[J]. 山东师范大学. 2008

[8] 韩彩英. 人文教育与大学外语教学 [J]中国高教研究 1999(5):64-65

[9] 谢敏. 大学英语教育中的人文素质教育探析. 贵州工业大学学报:社会科学版, [J] 2008(6) :154-155

[10］左焕琪. 外语教学展望. 上海. 华东师范大学, 2001,12

作者： 欧阳巍娜， 1980 年生，英语语言文学硕士，研究方向：英美文学，语言学

\section{References:}

[1] Wang Shouren. On the State of College English Teaching in China and its Future Development [J]. Foreign Languages in China, 2011, 08(5):4-11 
[2] Dai Weiping. Language Teaching of Linguistics Theory. Guangzhou: World Book Publishing Guangdong Ltd, 2014.7

[3] Du Shizhong. The Idea of Humanities Education [J]. Theory and Practice of Education, 1999(9):2-7

[4] Luo Hexiang. Strategies of Humanities Education in College English Curriculum [J]. Education Research Monthly, 2008(12):32-33

[5] Zhang Hong. On the Reform of China's College English Teaching from the Perspective of General Education [J]. Journal of Shanghai Jiaotong University, 2007:32-33

[6] Zhong Qiquan, Wang Xia, Wang Wenjing. Curriculum and Teaching Theory. Shanghai: East China Normal University Press, 2008.7

[7] Xi Feng. On Humanities Education in Foreign Language Teaching [J]. Shandong Normal University, 2008

[8] Han Caiying. Humanities Education and College Foreign Language Teaching [J]. China Higher Education Research, 1999(5):64-65

[9] Xie Min. On Humanities Education in College English Teaching [J]. Journal of Guizhou University of Technology (Social Science Edition), 2008(6):154-155

[10] Zuo Huanqi. Foreign Language Teaching Outlook. Shanghai: East China Normal University, 2001, 12

Author: Ouyang Weina, born in 1980, master's degree in English language and literature, research direction: English and American literature; linguistics. 